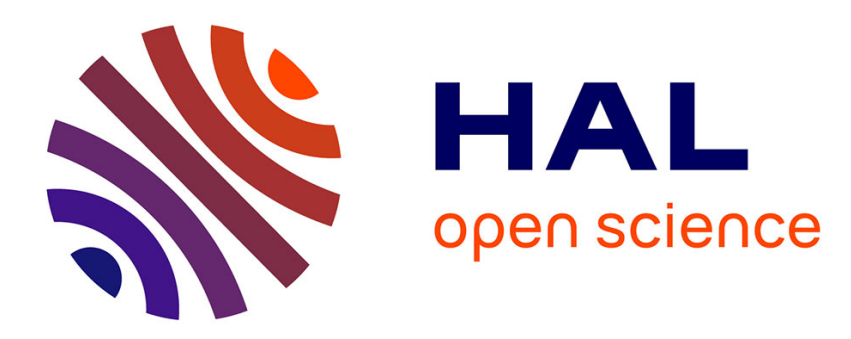

\title{
Parody, Terror and the Making of Forms: Blake's Aesthetics of the Sublime in The Book of Urizen \\ Hélène Ibata
}

\section{To cite this version:}

Hélène Ibata. Parody, Terror and the Making of Forms: Blake's Aesthetics of the Sublime in The Book of Urizen. Romanticism and Victorianism on the Net, 2012, 59-60, 10.7202/1013275ar . hal02458805

\section{HAL Id: hal-02458805 \\ https://hal.science/hal-02458805}

Submitted on 28 Jan 2020

HAL is a multi-disciplinary open access archive for the deposit and dissemination of scientific research documents, whether they are published or not. The documents may come from teaching and research institutions in France or abroad, or from public or private research centers.
L'archive ouverte pluridisciplinaire HAL, est destinée au dépôt et à la diffusion de documents scientifiques de niveau recherche, publiés ou non, émanant des établissements d'enseignement et de recherche français ou étrangers, des laboratoires publics ou privés. 
ARTICLES

\section{Parody, Terror and the Making of Forms: Blake's Aesthetics of the Sublime in The Book of Urizen}

Hélène lbata

...plus d'informations $\vee$

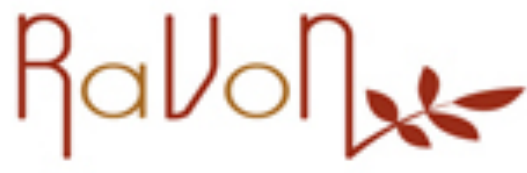

Romanticism and Victorianism on the Net

URI http://id.erudit.org/iderudit/1013275ar

DOI 10.7202/1013275ar

Un article de la revue Romanticism and Victorianism on the Net

Numéro 59-60, April, October, 2011

Copyright @ Université de Montréal, 2013

\section{Abstract}

In The Book of Urizen, Blake's subversion of authoritative discourses includes a critique of Enlightenment aesthetics, and in particular a parody of the contemporary conception of the sublime. At the same time, however, the aesthetics of terror are displaced onto new grounds, as the artist draws attention to creative anxiety and the endless and laborious production process. This new emphasis, we show, is one of Blake's most significant contributions to the debate on the sublime. As the self-reflexive dimension of The Book of Urizen attests, it is anchored in his own practice and in his awareness of the incommensurability of formal intentions and execution.

The mid-179os were years of doubt and frustration for William Blake. His enthusiasm for revolutionary causes had been dampened by a growingly repressive atmosphere, antijacobinism and censorship, and he was gradually withdrawing into solitary artistic production, transforming political commitment into a private aesthetic and poetic rebellion. The dark illuminated poems of those years mark the emergence of Blake's personal mythology and aesthetics out of the artist's disillusionment and 
difficulty to deal with the reactionary context. Among them, The First Book of Urizen (1794) ${ }^{[1]}$ stands out as one of Blake's most satiric and subversive works, even though its critical dimension is already being absorbed into the personal myth.

The poem relates the creation of the material universe by the "primaeval priest", Urizen, as a separation from Eternity and a fall into vacuity from which the only relief is the creation of material forms. Urizen's creation of a vast and "petrific" "dark globe" (E73) [2] is followed by Los's creation of a material form for Urizen, who has become a "formless immeasurable death" (7:8; E74) and whom he undertakes to bind at his forge. The lengthy process fuses into the production by division of Los's own female emanation, Enitharmon, and his fathering of Orc. Finally, the sons and daughters of Urizen are born, to spread their father's "Net of Religion" (25: 22; E82) but also to provide the potential for a liberating exodus (28: 19-23; E83)

Several commentators, focusing on the poem itself, have highlighted the centrality of biblical parody or critique. The book has been interpreted as the "Bible of Hell" which Blake had announced in The Marriage of Heaven and Hell, a rewriting or parody of Genesis (Tannenbaum 201-24), a reflection about the performative nature of language in Genesis 1 (Esterhammer 114-125) and a political stance against the instrumentalization of religion as a means to control society (Worrall 19-24). The complexity and indeterminacy of The Book of Urizen, with its variable textual and visual order (changing from copy to copy), its missing plates and its redundancies, have been identified as possible allusions to biblical textual incoherences, of which Blake would have been familiar through the work of Alexander Geddes (McGann 303-24); the unusual visual format, in particular Blake's choice to organize the text in columns, seems to confirm this biblical subtext. [3]

Although biblical critique has received much attention, it is only one facet of subversion in TheBook of Urizen, where the reflection about formal creation has both cosmogonic and artistic significance. The parody of authoritative discourses also includes, as I will try to show, a critique of the prevailing aesthetic discourse, and of the contemporary reflection about the sublime. From a rhetorical point of view, as Angela Esterhammer has convincingly shown, Blake's use of performative utterances may be traced back to Longinus and his praise of the sublime power of creative language, which finds its most striking expression in the words of Elohim in Genesis 1 (116-17). By presenting Urizen's language as an instrument of power and coercion rather than as positively creative, Blake may be understood to question this Longinian link between language, power, and sublimity.

At the same time, the text's imagery of terrifying vastness, infinity and vacuity would have brought to mind familiar descriptions of the natural sublime, those immeasurable physical manifestations which were believed to cause an uplifting experience in the viewer. And the illustrations' cosmic, elemental spaces, their opaque darkness, hellish flames and colossal monolithic figures owed much to the contemporary British taste for what Morton D. Paley has described as the "apocalyptic sublime." Both developments were thematically inspired by the extensive eighteenth-century aesthetic debate, which 
under the aegis of the school of empiricism, had directed its attention to natural causes and psychological explanations of the experience of the sublime, and emphasised the role of terror as the source of intense, heightened aesthetic appreciation. The most influential essay in this debate, Edmund Burke's Philosphical Enquiry into the Origins of our ideas of the Sublime and the Beautiful (1757) had given canonical form to this aesthetics of terror. And a prolific imagery of natural vastness, magnitude, obscurity, confusion or power, but also of Homeric, Miltonic or biblical scenes had found its way into the textual and pictorial representations of the time.

Blake's debt to this pervasive imagery, in The Book of Urizen, as in most of his prophecies, is undeniable. His critical position, however, makes this particular illuminated poem a true contribution to the contemporary debate on the sublime. To begin with, in a poem which narrates the fall from Eternity into a narrow world of sense, his use of the idiom is subversive, and parodic of the empiricist approach. The textual and visual references to sublime terror can indeed be interpreted as evidence of sensory limitations rather than mental exaltation, since only the perceptually limited mind can be terrified by physical magnitude.

More importantly, as I will argue, the poem and its illustrations give a challenging new significance to the aesthetics of terror that the eighteenth century relished so much. The contrast between the poem's cosmic imagery and the technical difficulties of book production points to a discrepancy, a sense of incommensurability, which is echoed in the book's open-ended and unstable nature, its variations in the order of the plates and in their individual finish. This indeterminacy, while possibly indicative of biblical parody, also suggests that Urizen should be seen as a work in progress, where the laborious process of artistic creation is exposed in all its anxiety. This realization appears perhaps most clearly in the book's self-reflexive dimension, and in the poem's thematics of form-making as a terrifying process.

Recent commentators have insisted that the sublime is not an experience that transcends the human (for example by lifting the mind beyond what it can sensibly perceive or represent), but that it actually takes place within the very human struggle to give form to what exceeds sensible apprehension. Writers such as Jacques Derrida or Jean-François Lyotard, interpreting Kant's "Analytic of the Sublime" in the Critique of the Power of Judgment, have identified a discrepancy between what the mind can intuit and what it can represent as the crucial moment of the sublime, one which opens the endless, terrifying, but also elating, process of form-making. What I would like to show is that The Book of Urizen presents a sublimity that is akin to such a conception, and that its indeterminacy is a transposition of the Burkean aesthetics of terror within the very process of form-making. Although these features can be found in most of Blake's prophecies, and the terror of form-making is actually later integrated into the cycle of Generation, I have chosen to look more closely at Urizen, because its unstable form reflects the emergence of this strong sense of creative anxiety, in a context of aesthetic uncertainties, and at a time when Blake was laboriously experimenting with a new medium, colour printing. 
The analysis will first examine how The Book of Urizen undermines the conventional representations of the sublime, through an ironic counterpoint of text and image, and a visual parody of Burkean aesthetics. It will then highlight the seriousness of Blake's reflection, which transforms the passive terror of the Burkean experience of the sublime into the active terror of artistic production, driven by the necessity to produce forms. Finally, it will show that this profound anxiety to give form, to match the artist's imperfect production with his aspiration to perfection, is the ground on which Blake redefines the sublime, in terms of the ongoing process of artistic creation.

\title{
I. A Parody of Burkean Aesthetics
}

Blake's radical defense of vision and imagination was in contradiction with the sensationist premises of much of the British aesthetic debate of his time, and this hostility found its most vocal expression in his marginalia to Reynolds's Discourses on Art. Although there is no similar confrontation with Burke, at the time of the production of Urizen an implicit debate with the author of the Philosophical Enquiry was taking place, as Blake's dislike of the latter's aesthetic views was compounded by political antagonism.

In the 1790s, Edmund Burke would have embodied everything that Blake stood against. From an aesthetic and philosophical point of view, the Enquiry's emphasis on the material and psychological causes of the sublime deeply challenged his visionary conception, as he himself later made clear in his annotations to Reynolds's Discourses on Art:

\begin{abstract}
Burke's Treatise on the Sublime \& Beautiful is founded on the Opinions of Newton \& Locke on this Treatise Reynolds has grounded many of his assertions. in all his Discourses I read Burkes Treatise when very Young at the same time I read Locke on Human Understanding \& Bacons Advancement of Learning on Every one of these Books I wrote my Opinions \& on looking them over find that my Notes on Reynolds in this Book are exactly Similar. I felt the Same Contempt \& Abhorrence then; that I do now. They mock Inspiration \& Vision Inspiration \& Vision was then \& now is \& I hope will always Remain my Element my Eternal Dwelling place.
\end{abstract}

E660

To aggravate the intellectual conflict, with his political speeches and Reflections on the Revolution in France (1790), Burke had become the active spokesman of antijacobinism. Blake's dislike of Burke's political beliefs was made explicit in Europe (1794) where, as David Erdman has shown, the crouching figure with a dagger on plate 1 would have been recognized as a reference to Burke's theatrical call to arms in Parliament, in December 1793, during which the speaker had suddenly taken out a dagger and thrown it on the floor. The profile of Blake's assassin is very similar to Gillray's caricature of Burke in The Dagger Scene, and leaves no doubt as to how to identify the figure (Prophet 218-19). 
Recently, several commentators have demonstrated the extent of Blake's debate with Burke and the Reflections in The Book of Urizen. A. Harris Fairbanks thus argues that Urizen's "Laws of peace, of love, of unity" (4: 34; E. 72) reveal the sinister implications of Burke's unifying vision of Britain as a country of political and social consensus (79). He also sees in Urizen's “Net of Religion” (25: 22; E. 82) a likely critique of Burke's belief that a state religious establishment is necessary to create "an wholesome awe" (Burke Reflections 190) on the people (79). Andrew Cooper carries this argument further, when he observes that “Urizen's opening satire on the abstractions of negative theology extends ... to Burke's distinctly Whiggish theory of the sublime," which Blake parodies as an instrument of political mystification, as "an 'idea of Power' that transcends representation" (214).

Such interpretations rightly identify the imagery of awe and terror in Urizen as an instrument of power, thus conflating Burke's aesthetic and political theories. What I would like to argue, however, is that as the Burkean sublime permeates the imagery of the poem, it also articulates a major shift from political commitment to aesthetic speculation. Even though Urizen is still challenging Burke's conception of power, the use of sublime thematics suggests that the political critique is becoming fused into and displaced by a new reflection about artistic production, and the poem may be understood as one of Blake's main contributions to the contemporary aesthetic debate.

A central aspect of The Book of Urizen is its subversion of the main philosophical premise of the Burkean sublime, that is to say the idea that the sublime originates in sensory perceptions which exceed our rational grasp. The eponymous figure, whose name can be understood as a pun on "your reason" or "horizon," stands for rational and sensorial binding. He creates a world of single vision, where reason and the shrunken physical senses become the narrow windows of perception, the "narrow chinks" of man's "cavern" as Blake puts it in The Marriage of Heaven and Hell (E39). Overwhelmed by anything which exceeds this single and limited vision, the mind in such a world experiences the feeling of terror which Burke describes as central to the experience of the sublime, but which Blake shows to be a reflection of perceptual limitation.

The poem addresses these issues explicitly in the opening cosmogonic pages of the Preludium and the first three chapters. In the introductory lines, the Eternals isolate Urizen by opening a space for him: "a place in the north,/ Obscure, shadowy, void, solitary" (2: 3-4; E7O). As the rhythmical and semantic parallels suggest, the list of adjectives is a likely reference to Burke's list of "privations" which are sources of the sublime: "Vacuity, Darkness, Solitude, and Silence" (65). The abyss of nothingness within which the creation of the physical universe is to take place, then, is to be understood as a parodic Burkean environment, in all its empty vastness and darkness. While this emphasis on emptiness undermines the sensationism of Burke's theory, it also challenges its psychological basis: the "Terror" and "horror" (3:1; 3: 27, E70-71) consecutive to the opening of the abyss are not "the sort of delightful horror, which is the most genuine effect, and truest test of the sublime" (Burke, 67), but the horror of mental vacuity. 
The opening plates further the critique by describing the liminal chaos from which Urizen's world is to be created as a formless environment fraught with dismal sublime imagery. An "abominable void," "desolate mountains," "black winds of perturbation," a "forsaken wilderness/ Of beast, bird, fish, serpent; \& element, / Combustion, blast, vapour, and cloud" (3: 4, 11, 12, 15-17; E70) crowd into the unrepresentable picture, followed by a rapid succession of "bleak desarts" (4: 1; E71) or "dark desarts" (5: 14; E73), of a "void immense, wild, dark, \& deep" (4: 16; E72), and an "ocean of voidness unfathomable” (5: 11; E73). This imagery closely recalls Burke's exhaustive enumerations of sources of the natural sublime in the Philosophical Enquiry. By transforming this natural sublime into a picture of vacuity, through the use of negative qualifiers, Blake reveals his heightened awareness of the anxiety of nothingness that underpins Burke's theory. The critic is therefore also a shrewd interpreter.

Indeed, the Burkean subtext permeates Blake's poem to such an extent that the distinction between parody and emulation is not always clear. At times, this subtext subtly works its way into Blake's imagery through an indirect process of creative assimilation. Thus, the image of the "vast forests" (3: 23; E71) in which Urizen's dark creative activity takes place, is indirectly derived from Burke's statement that the sublime "comes upon us in the gloomy forest, and in the howling wilderness, in the form of the lion, the tiger, the panther, or rhinoceros" (6o-61). It has in the meantime been mediated by the ambiguous and fascinating "Tyger" of the same year, "burning bright/ In the forests of the night." Although there is no mention of a tiger anymore in Urizen, the Burkean imagery has been appropriated and adapted: the vastness, darkness and forests remain, but the emphasis is now on the measuring creator within them who had dared frame the tiger's "fearful symmetry."

At this textual level, it is actually difficult to distinguish formal parody from a genuine interest in some of the poetic effects described by the Philosophical Enquiry. Burke had said of Milton's description of Satan in Book I of Paradise Lost: "The mind is hurried out of itself by a crowd of grand and confused images, which affect because they are crowded and confused" (57). Reading the opening chapters of The Book of Urizen, where the crowding and confusion of sublime imagery is almost excessive, one may wonder whether Blake, who greatly admired Milton, is emulating Milton, emulating the Miltonic effects described by Burke, or parodying Burke.

To fully appreciate Blake's parody of the Burkean sublime in Urizen, it is necessary to contrast the text with its illustrations, where the subversive intentions appear more clearly. W.J.T.Mitchell compares Blake's illuminations to musical counterpoints, to explain how text and image are played off against one another, as separate but interdependent sequences (9). This form of interaction is used to great effect here. Where the text's imagery is dizzying in a manner Burke might have praised, the accompanying designs, by undermining the conventional visual idiom of the sublime, highlight the book's critical dimension.

In these designs, the cosmic vastness, terrifying void and elemental chaos of the poem's opening chapters are transposed as narrow and oppressive spaces, without any perspectival distance, where 
massive monolithic figures press against the picture plane. This contrapuntal visual message emphasizes the finiteness of perception in Urizen's world, rather than the sense of spatial immensity experienced through such finite perception. It shows through recurrent images of imprisonment and petrifaction that vacuity, vastness and darkness are not sources of sublimity, but projections of a mind shrunk by selfish closure.

There are many ways in which TheBook of Urizen turns upside down the conventional visual representations of the sublime. More than in any other illuminated book, Blake uses graphic format, representational scale and printing technique to parody the sensationist premises of the Burkean sublime.

The small printing format of the Urizen books is not unusual in Blake's early production, but in the context of explicit references to the Burkean sublime, its use is definitely ironic. The vast cosmic expanses that surround Urizen's creation are shrunk to small book format and entirely filled by the actors of the drama, of proportionally massive appearance. As Mitchell notes, the cosmic perspective of the poem is in sharp contrast with Blake's choice to "zoom in" on his figures and to eliminate "the relief provided by a larger perspective" (108-109). Even though this effect is partly due to the colour printing medium itself, which precludes the fine representation of small figures, Blake has made the most of such a constraint, by demonstrating what a visual transcription of Burkean aesthetics could be. The visual actors become simultaneously images of colossal and awe-inspiring power in the physical world, and figures of solitude and vacuity, enclosed as they are in such shallow and narrow spaces. More importantly perhaps, those claustrophobic spaces are a lucid, if biased, interpretation of what vastness, magnitude, and infinity mean in The Philosophical Enquiry. According to Burke, "the great and sublime in nature" cause such "astonishment" in the soul, that "all its motions are suspended, with some degree of horror. In this case the mind is so entirely filled with its object, that it cannot entertain any other, nor by consequence reason on that object which employs it" (53). The many images of spatial closure and compression in The Book of Urizen may be seen as a parody of the mind in such a state, so entirely dominated by its external perceptions that it actually perceives nothing. Instead of attempting to visualize the cosmic Burkean environment of the text, Blake has produced contrapuntal representations of mental imprisonment in the designs.

In one of the most effective representations of such a state, a bearded figure whom we may identify as Urizen is depicted sitting, bound by chains round his wrists and ankles, with his legs and arms pressing against his chest, and with the image frame pressing on all sides (Plate 22). [4] The figure appears flatly against a background of rocks and rays around his head, so as to create an effect of utter compression. This state of closure and petrifaction is heightened by the figure's closed eyes (from which tears are rolling down in some versions), which suggest that his imprisonment is primarily mental. In copies A and C (The William Blake Archive, The First Book of Urizen, copy A, pl. 3, copy C, pl. 12), the stark and almost monochromatic use of browns effectively conveys a sense of emptiness and desolation. 
Another strikingly claustrophobic representation of Urizen shows him squatting, his head and beard lowered between hunched shoulders, one protruding leg, and arms framing his whole body (Plate 9). He is once again so closed upon himself that he almost forms a rigid rectangle, mimetic of the picture frame. In the colour printed versions, the surrounding opaque and reticulated printed colours suggest that he is compressed within rocks, of which he appears to have become a mineral component. In copies D and F (The William Blake Archive, The First Book of Urizen, copy D, pl. 8, copy F, pl. 11), the granulated appearance of colour printing very convincingly conveys Urizen's mineral surroundings as well as his own petrifaction, and the overlapping of colours enhances the sense of oppressive fusion. Copy A (The William Blake Archive, The First Book of Urizen, copy A, pl. 23) achieves a similar effect through rather different means: instead of filling the image with several colours spreading into one another, Blake has only coloured the shape of Urizen and filled the shades with dark ink around it, daringly leaving the rest of the rocks (and the page) blank. The sharp tonal contrast, and the emptiness of figurative elements, very efficiently convey the barrenness of Urizen's universe.

The Book of Urizen, Copy G, Plate 11, Courtesy of the Library of Congress

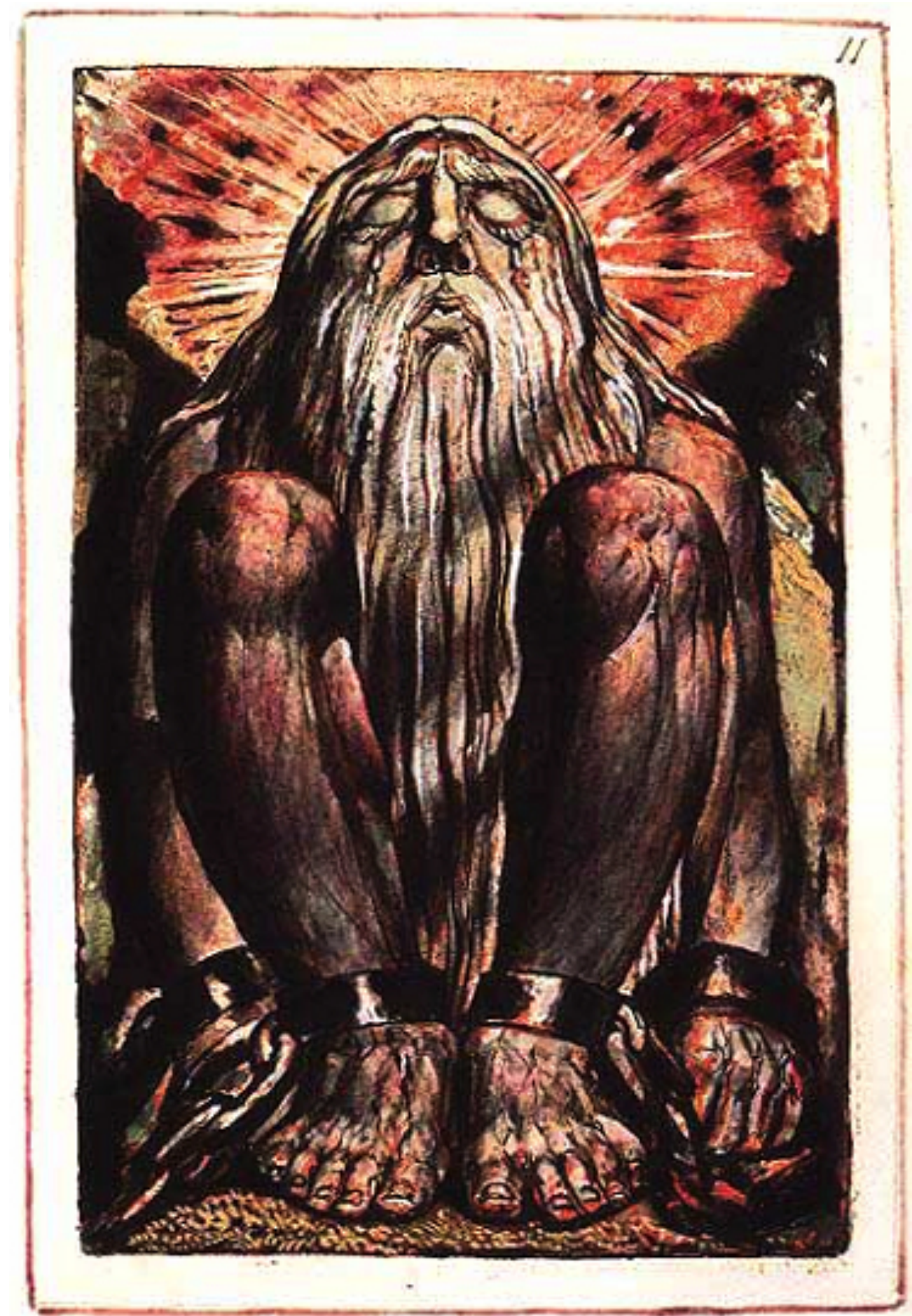


The First Book of Urizen, Copy A, plate 23, Courtesy of the Yale Center for British Art.

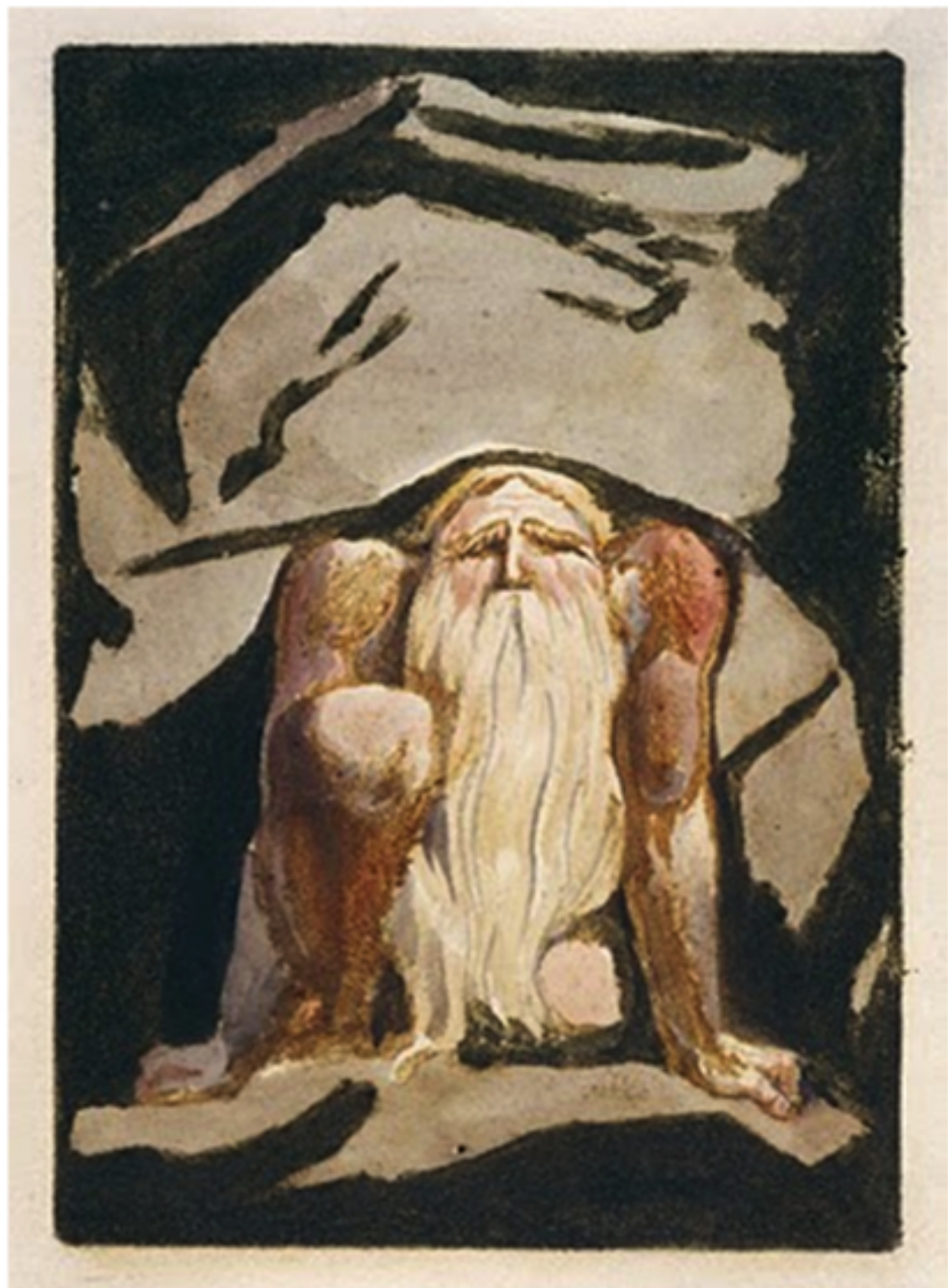

$\rightarrow$ Voir la liste des figures

Literally, these are two images of Burkean terror, of a mind "so entirely filled with its object, that it cannot entertain any other.” The parody consists in presenting the Burkean sublime as a diminished state of mental closure, rather than as images of natural magnitude. These intentions are perhaps most obvious on Plate 12, another isolated illustration representing Urizen's mental passivity and oppression. Here, he is shown immersed within the ocean of nothingness that now divides him from Eternity, which the text refers to as an "ocean of voidness unfathomable" or "infinite ocean" $(5: 11,35$; E73). Instead of attempting to visualize the infinity or unfathomable depth of the watery extent, the illustration shows Urizen faintly extending his arms, only to reach the corners of the picture frame. His legs are still unfolded, and the openness of the rest of his body (his arms and beard in particular) only conveys a sense of dissolution into watery vacuity. Burke had called the ocean "an object of no small terror" which could fill the mind much more, for instance, than a vast plain (53-54). This plate shows 
not the terrifying vastness of the ocean, but the passivity of a mind overwhelmed by the sensory perception of immensity.

Such plates are efficient and literal representations of the Burkean sublime inasmuch as Blake has chosen to visualize the psychological state of terror and passivity conducive to it, rather than the visible sources of it in the world of experience. In this respect, he goes against the pictorial practice of his time, which sought the sublime in large formats and representations of mountains, oceans and wildernesses. His choice even seems to confirm Burke's conviction that the visual artist's attempt to convey physical vastness will always fall short of the works of nature: "Designs that are vast only by their dimensions," the Enquiry stated, "are always the signs of a common and low imagination. No work of art can be great, but as it deceives; to be otherwise is the prerogative of nature only" (70). Blake's small formats, however, are parodic of Burke's sensationist premises. The compressed representations of his "giant forms" and cosmic spheres undercut a conception of sublimity dependent on the sensory perception of magnitude.

In addition to this parodic dimension of format and scale, Blake's unusual use of colours, tones and textures in Urizen also seems to address some of the aesthetic premises of the Philosophical Enquiry. This is especially the case in copies A, C-F and J, which were probably all produced in one edition in 1794 (Viscomi 279-80). In these versions, Blake used the colour-printing method which may be found in many of the illuminated books produced in 1794 and 1795. As Essick and Viscomi have explained, the technique he had devised allowed him to apply all his colours directly onto the printing plate, simultaneously, and to print them all in one pull. To this end, he used water-miscible paints mixed with "size" (glue), which prevented the colours from spreading and overlapping, and used the shallows and reliefs of the plate to increase the range of colour and expression (Viscomi 121; Essick and Viscomi, 78). The resulting mottled appearance was due to the added use of oil-based inks, and to their interaction with the water-miscible paints. In the early versions of Urizen, the reticulation, opacity and overlapping of colour surfaces give them a raw and unfinished quality that matches the thematics of chaos and formal indefiniteness in the text. In many designs, the figures of the protagonists seem to emerge without contours of their own from the darker granulated surfaces around them, as if their forms were extracted out of the surrounding elemental chaos. In most cases, in fact, there are relief etched outlines, but they are usually imprecise and covered by colour impressions for which they merely provide guidelines. In some cases, contours have been added, or suggested through the watercolour finish of the darker areas around the figures, although such corrections are not consistent from copy to copy.

The indistinct effects of colour printing could have been parodic of Burke, who had stated that formal indeterminacy stirred the imagination much more powerfully than clear ideas or representations: "dark, confused, uncertain images," he claimed, "have a greater power on the fancy to form the grander passions than those have which are more clear and determinate" (Enquiry 58). As is well known, Blake's writings on art in the 1800 s were to oppose to such indeterminacy a conception of the sublime as the 
expression of imaginary strength, to be found in "Minute Neatness of Execution" (E 646) rather than in the "Blots \& Blurs" of colourists like Rembrandt or Rubens (E 576).

Blake's predilection for colour printing in the mid-179os, however, indicates more uncertain and troubled aesthetic purposes. Colour printing clearly provided some aesthetic rewards, like the stunning colour and textural effects that are found in the large colour prints of 1795. And the roughhewn figures of Urizen, crudely modeled by the coarse-textured ochre shades of relief-etching, as if carved out of thick elemental darkness, have a raw visual power of their own. Nonetheless, the medium was also intractable and possibly unsatisfactory. The fact that its effects were corrected in the hand coloured versions, copy B and the more mature copy G (produced in 1795 and 1818 respectively), [5] suggests that Blake intended to produce more definite designs.

Consequently, while the formal characteristics of the Urizen prints may be a means to address the Burkean aesthetics of indeterminacy, they can also be interpreted as illustrating the trials of formmaking itself. The pervasive theme of creative terror in the text suggests that Blake was not only critical of such indeterminacy, but aware that his own creative process was threatened by it. This terror strikes the protagonists as the forms of their own making rise before them. It overcomes Los, as he shapes the changes of Urizen: "In terrors Los shrunk from his task: His great hammer fell from his hand" (13: 20-21; E77). It strikes the Eternals who watch Los shaping the "first female form" (18: 15; E78), Enitharmon: "Eternity shudder'd when they saw,/ Man begetting his likeness,/ On his own divided image" (19: 14-16; E79). It even prevails over Urizen, as he encounters the monstrous forms of his rational and divisive production through "A fearful journey, annoy'd/ By cruel enormities: forms/ Of life on his forsaken mountains" (20:49-50, 23: 1; E81). It is not the "delightful horror" of the Philosophical Enquiry: it is the anguish of creative paralysis and failure. Although this motif recurs in the later prophecies, its appearance in the Urizen books, at a time when Blake was experimenting with his intractable colour printing medium, suggests that it may be interpreted as a mise en abyme of Blake's own productive anxiety.

\section{Between Form and Formlessness: The Abyss of Representation}

The terror which Burke saw as central to the sublime was a surrender of mental faculties, leading to an uplifting transcendental experience. The terror of form-making which is described by the poem and which takes place in its own illuminations, is immanent to the dynamic process of production. By drawing our attention to this very process, Blake goes beyond parody, and suggests how the sublime could be found there, in this compelling driving force of creation: the fear of nothingness and formlessness. 
In his essay on "The Sublime and the Avant-Garde," Jean-François Lyotard redefines the sublime as located in the here and now of artistic production, in the desperate tension towards form, towards novelty, which drives art forward. He sees the avant-garde artist as subject to "a feeling of anxiety" linked to "the possibility of nothing happening," and locates the sublime in the fact that a painting (or other work of art) still happens. Significantly, he considers this tension to be central to the Burkean sublime, which is driven by the terror of absolute privation. The "major stake" of Burke's aesthetic, Lyotard claims, is "to show that the sublime is kindled by the threat of nothing further happening," a menace which is distanced by art, whose production brings momentary relief from nothingness, and therefore "delight" (198-99; 204).

The Book of Urizen, beyond its parodic intentions, makes obvious these implications of Burke's emphasis on terror. It pins down the anxiety of absence that is at the core of the Philosophical Enquiry, by selecting, as we have seen, a Burkean imagery of vacuity in its opening pages. And by fusing into this imagery the original motif of Urizen's "enormous labours," of his "activity unknown and horrible," (3: 20-22; E71) it also demonstrates the artist's fear of creative paralysis as well as his urgency for form to emerge out of formlessness, a theme which was to become central to the later prophecies. In a recent article, Aria Chernik argues that the "abominable void" which is created for Urizen in the Preludium can be read as an independent productive and vital space, a place for the expression of Urizen's energy, and consequently a place for what she calls the "exemptive sublime" (Chernik, § 22-23). Such an interpretation correctly outlines the link between absence and creativity. Yet, following Lyotard's argument, I would argue that creativity, in this case, is strongly constrained by the urgent need to extract form out of nothingness, and owes as much (if not more) to anxiety as it does to freedom.

In the colour printed versions of Urizen, this struggle for the emergence of form is more strikingly visualized than in the other illuminated books, as Blake's monolithic figures are extracted from elemental chaos and from the printing medium itself. In La Vérité en Peinture, Jacques Derrida claims that the main point of departure of the sublime from the beautiful is the question of delineation. A contour, Derrida says, is what gives form to the beautiful. The sublime, on the other hand, is found in a formless object, in what resists delineation and consequently the masterful control of the artist. It is found particularly in raw nature, and in the "colossal," the raw form beyond proportion and measure, which is an intimation of infinity and cannot be given clear boundaries (139-146). The "giant forms" of Urizen, which so intentionally display their resistance to delineation, seem to intentionally point at this indistinct locus where forms cease to be beautifully contained. The clumsy or absent outlines open a frightening abyss by blurring the limit between the finite and the infinite, as well as the indefinite. This abyss is where representation becomes impossible, by exceeding the boundaries of the beautiful.

Blake's seemingly unfinished designs draw our attention to such a representational gap, and to the anxiety of production caught in the liminal state between form and formlessness. His exploration of this daunting threshold, I believe, is where the reflection goes beyond the critique of Burkean aesthetics and places the sublime at the heart of artistic creation. 
The artist was not alone in realizing that the sublime was intrinsically linked to the anxiety and frustration of the productive process. Coleridge's reading of Kant was to lead him to a similar awareness, a few years later, making him claim:

The grandest efforts of poetry are where the imagination is called forth, not to produce a distinct form, but a strong working of the mind, still offering what is still repelled, and again creating what is again rejected.

Coleridge, however, believed that such a strong working of the mind could not occur within "the narrow limits of painting" (2: 496). The Urizen designs, on the other hand, make it clear that the sense of urgency arising from the tension between form and formlessness was a major concern of visual production. Their self-reflexive dimension, as we are going to see, highlights some of the predicaments of visual creation, caught between the necessity to make forms, the refusal of definite formal binding, and the endless dissatisfaction with the product of such an activity.

\section{Self-parody, Self-reflexivity, and the Sublime as Productive Process}

Creative anxiety and the frustrating process of formal production is a central concern of The Book of Urizen, and may account for a number of self-reflexive designs which, through their depiction of Urizen's book-making activity, suggest a critical mise en abyme of Blake's own work. As early as the title page, Urizen is visually introduced as a maker of books, and the book of Urizen may be understood as the book made by Urizen, referred to on plate 4 as "the Book/ Of eternal brass, written in my solitude" (4: 32-33; E72). Significantly however, the textual reference to Urizen's book-making activity is removed from several versions, where plate 4 does not appear, whereas its visual counterpart is an essential part of the sequence of designs, and one of its most stable elements. The title page, which shows Urizen in the process of producing his book, and the plate which shows him displaying the "finished" product (Plate 5) anchor the visual sequence in a reflection about its own making. One aspect of this reflection about the book is biblical parody: the "Book/ of eternal brass" is a book of laws (4:34-35; E72), if not The Book, and its two visual representations evoke the Mosaic tablets. Nevertheless, the fact that the mise en abyme is a permanent feature of the designs whereas the textual reference is unstable suggests that visual concerns are essential, and that Urizen should also be seen as a figure of the artist. What is at stake is the production of visual forms, or rather its unfinished process.

The Book of Urizen, Copy G, Plate 1, Courtesy of the Library of Congress 


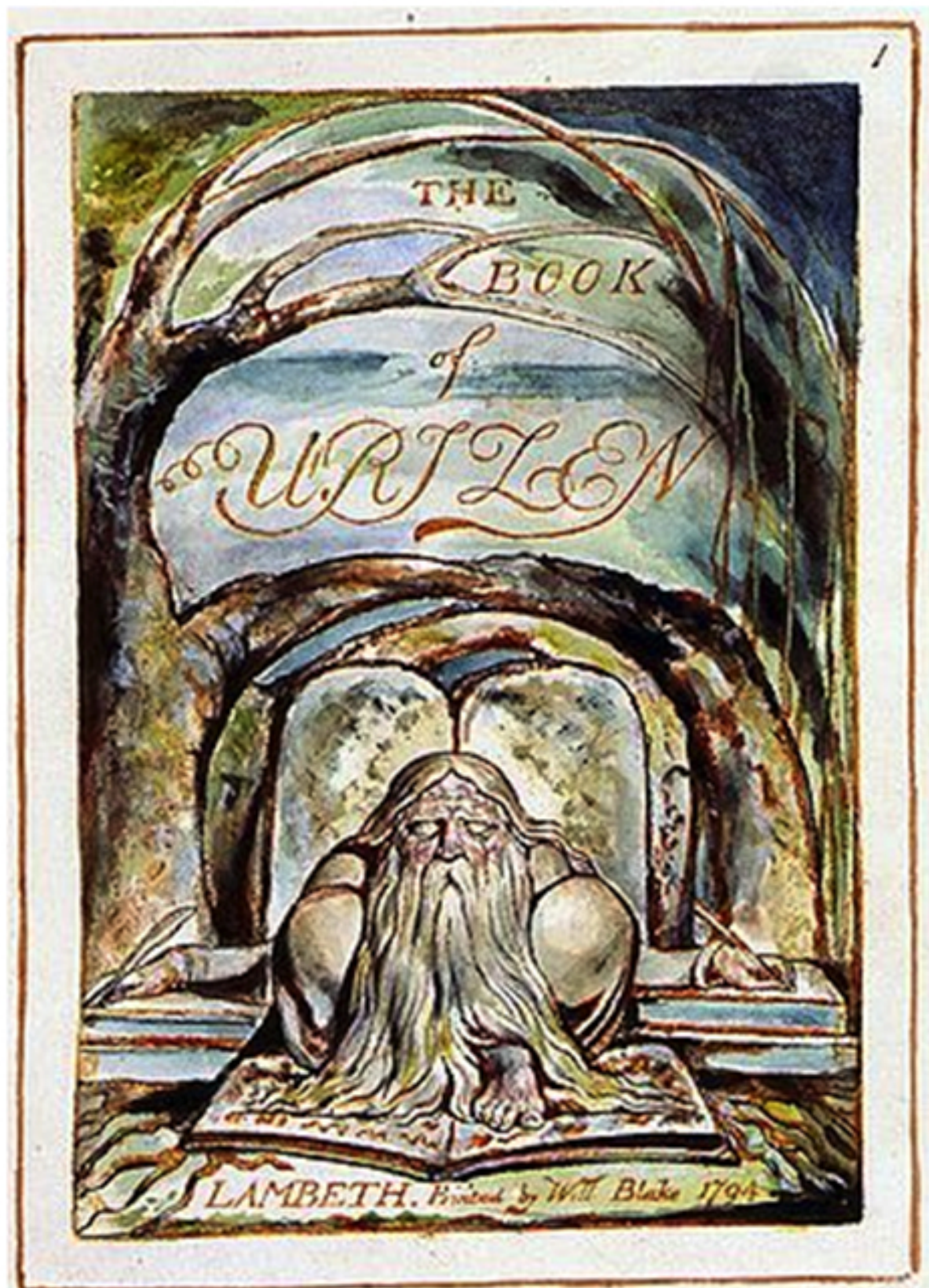

$\rightarrow$ Voir la liste des figures

The Book of Urizen, Copy G, plate 5, Courtesy of the Library of Congress 
(Viscomi 119-21; Essick and Viscomi 74-103), instead of colouring the image after having printed the text and outlines. Yet, the process was time-consuming and, especially in the production of Urizen, form had to be "brought back through finishing" (Viscomi 121) after the colour from the shallows had spread over the outlines. The fragmentation that colour printing was meant to overcome consequently reappeared in new productive stages, with the necessary extraction of form out of colour. It also became more difficult to fuse image and text on the same plate: in this early experiment with colour printing, there are more isolated plates without text than in any other illuminated book, as if Blake's laborious engagement with his printing medium led him to focus his energy on the simpler impressions of designs without text.

It is possible then that Blake would have felt his production to be almost as divided as Urizen's, in spite of his desire for completeness. The striking variety in the degree of finish from design to design and from copy to copy reflects his difficulty to choose between the raw but immediate prints and the more complex hand-finished ones. Thus, copies A and C, where hand colouring is sparingly used, have a simplicity of effect that is quite original, but they appear unfinished. Copies D and F contain more watercolour finish, and are richer in colour effects, but lose this powerful immediacy. Such hesitations, the instability and open-endedness which these variations reveal, suggest that Blake did not consider his book a finished product. Instead, the range of effects and plate order displays his own reflection about what a finished work of art may mean, and whether such a finished product is actually desirable.

Plate 5 makes it clear that Blake was preoccupied by the idea of the finished work of art, and the realisation that the artist's labour, his striving for completion, was endless (The William Blake Archive, The [First] Book of Urizen, copy A, pl. 8, copy C, pl.6, copy D, pl. 4, copy F, pl.4, copy B, pl. 6, copy G, pl.5). There, Urizen authoritatively displays his finished book, which in several colour-printed copies is an indistinct muddle of brown blots, and in copy D, where the impression is completed by hand colouring, a rich palette of brown and primary colours. It is only in the later version of the book, copy $\mathrm{G}$, that one can finally discern what looks like incomprehensible hieroglyphs, the hermetic code of Urizen's law. This book within the book is in all cases an image of abstraction, or formlessness, the “Blots \& Blurs" of an incompetent artist if we look at it in the light of Blake's later writings. In each copy, however, it is a clumsy but stylistically mimetic version of its container. It is muddled where colour printing is used in its simple immediacy, brightly coloured when watercolour finish is used (copy D), and detailed where Blake has replaced colour printing by a combination of relief etching and hand colouring (copies B and $\mathrm{G}$ ). The image consequently becomes one of the most striking examples of reflexivity in the illuminated books. Urizen's triumphant display of his unfinished work as a finished product might be understood as an ironic commentary on the artist's own dissatisfaction. It may also be interpreted as a visualisation of what artistic production should not be: muddled shapes bound in “eternal brass”. In any case, it sheds light on Blake's compelling struggle to resist formlessness, to make sense out of a chaos of colours, and to produce forms that are not bound in an illusion of perfection. It also suggests that, contrary to Urizen, he either does not consider his work finished, or is wary of the finished work that puts an end to artistic production. 
In many respects, The Book of Urizen can be considered as a work in progress, or at least one that presents itself as such. There is a denial of closure in the variable order of the plates, the use of designs without texts as mutable elements whose positions vary greatly from copy to copy, and the fact that no two copies contain exactly the same plates. The creative material almost seems to exceed the boundaries of the book, as if to challenge Urizen's controlling will, and in contrast with the rigidity of his "Book of brass." At the same time, the poem addresses the necessity to contain this material within some structure, some frame that prevents the narrative and visual sequences from becoming an unintelligible flux. Two plates illustrate well Blake's awareness of such a necessity and of the danger it entails. The Preludium (Plate 2), whose design and textual layout (in a single column) are reminiscent of Blake's earlier illuminated books, provides an initial narrative and visual anchoring. A narrator is introduced, who responds to the call of the Eternals as the piper of the Songs of Innocence answers the request of the laughing child in the "Introduction". The design, similarly, reassuringly harks back to the elegant motifs of the Songs, with the floating infant suggesting a parallel with the child or cherub as a symbol of inspiration in the text and designs of Innocence and Experience. Contrary to the other designs in Urizen, it can also be interpreted through familiar iconography, since the woman and child can be linked to emblematic representations of the flying soul accompanied by an angel (Worrall 27). Consequently, in this plate, literary and artistic convention is used as if to momentarily contain the strangeness of the rest of the book. The flowing style of the design suggests that this is by no means a constraining frame, only a means to give shape to the visual and verbal material that is being produced.

The Book of Urizen, Copy G, Plate 2, Courtesy of the Library of Congress 


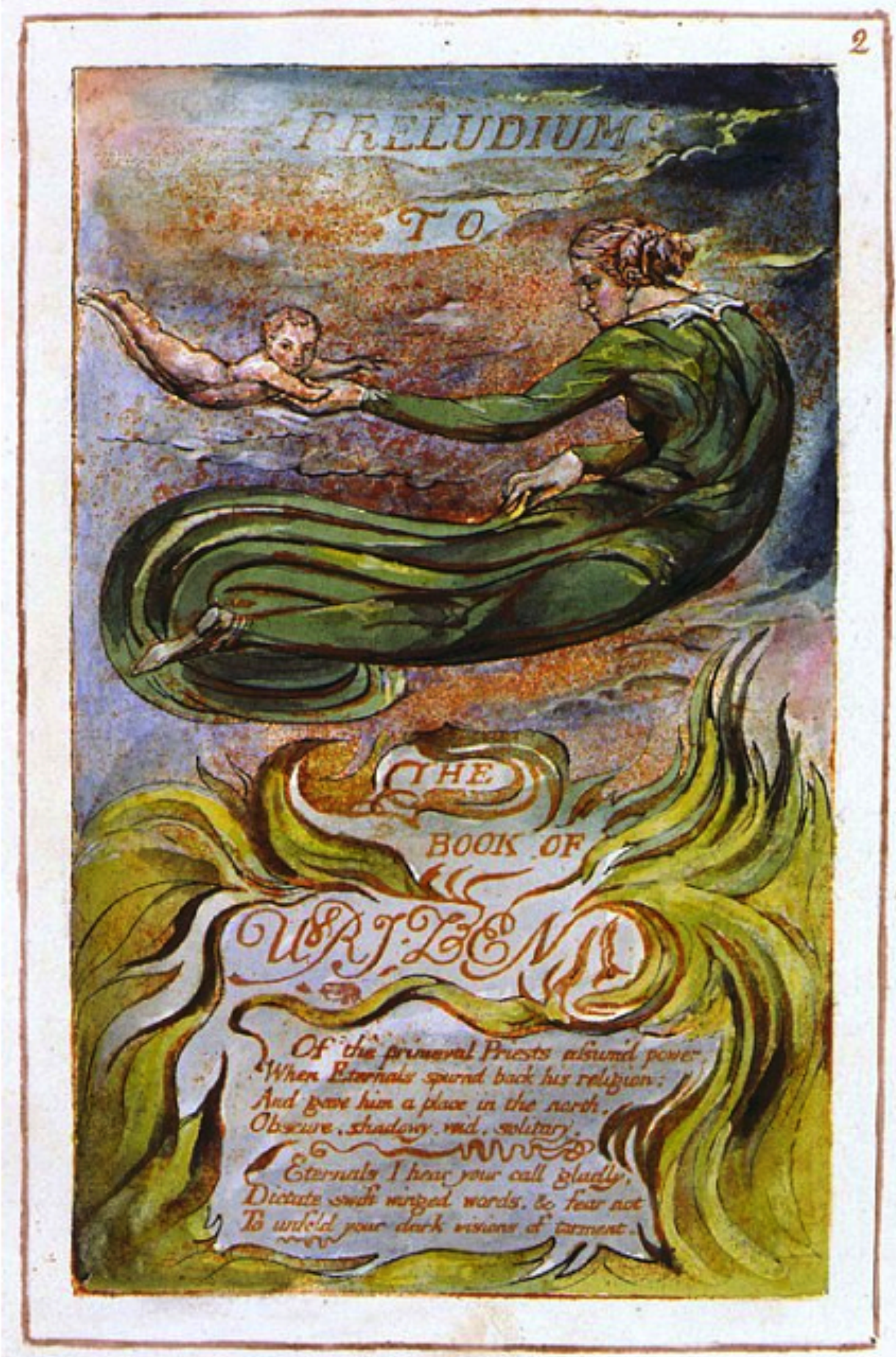

$\rightarrow$ Voir la liste des figures

In sharp contrast with this "open" beginning, plate 28, which states "The End of the first book of Urizen", and which appears last in most of the copies (The William Blake Archive, The [First] Book of Urizen, copy A, pl. 27, copy C, pl. 25, copy D, pl. 26, copy F, pl.26, copy B, pl. 26, copy G, pl.27), makes visible the terrifying outcome of too much framing. Urizen, whose artistic efforts have been marked by the wish to control form, and the sense of completion, is shown caught within his own Net, unable to escape from the rigidity of his own productions. The book ends on a note of defeat: formal boundaries, which are so necessary to artistic representation, have put an end to the process of artistic production. 
boundaries can be observed in the unfinished aspect of the colour printed versions. The occasionally remarkable colour effects obtained, the brilliance of raw impressions (in contrast with the duller appearance of watercolour) were intimations of the possibility of superior achievements in the medium. And large colour prints like the famous Newton later demonstrated that the impressions' reticulation, opacity and texture could indeed yield meaningful and outstanding effects. The designs of Urizen, however, have a tentative quality, which may have been due to the production constraints of the time, but which also make visible the medium's resistance to the artist's intentions. Creation is in progress, in the thematics as well as the making of the book, and the terror of form-making experienced by Los or Urizen may have been inspired by Blake's own struggle to channel his recalcitrant artistic materials into meaningful form. To some extent, the unruly nature of the colour printing medium is an efficient means to offset the pervasive imagery of closure and Urizen's controlling will; but it also underscores the limitations of artistic execution, and shows how daunting the endeavour to create meaningful form can be.

Some variations in the plates are intimations of the gap between intentions and execution, and of the open choice left by such a gap. This appears in another self-reflexive illumination, plate 24, which depicts the "forms/ Of life" produced by Urizen, the "cruel enormities" (2O: 50-51; E81) that he has begotten, his fours sons: an angry Fuzon surrounded by fire, a frightened Thiriel hurried through the air, a despairing Utha barely emerging from the waters, and a howling Grodna pulling himself out of the rock. All appear to be crudely hewn, with outlines formed by the edges of the colour printed areas, and their grotesque facial expressions and formal imperfection strikingly convey Urizen's disgust at his own creation: "Most Urizen sicken'd to see/ His eternal creations appear/ Sons \& daughters of sorrow on mountains/ Weeping! wailing!" (23: 8-11; E81).

This sense of formal inadequacy is reflected in the indeterminacy of the design itself: the removal of two of Urizen's sons from copies D and J, in which only Utha and Thiriel appear, shows Blake hesitating between semantic complexity and artistic accomplishment. The version of copy D (The Blake Archive, The First Book of Urizen, copy D, pl. 22) is visually more powerful than the impressions that contain four figures, although it seems to lose some of the elemental symbolism of those more detailed versions. The rich opacity and heavy texture of the printed colours, which are so convincingly evocative of a dark ocean and ominous sunset, more than make up for this loss of explicit symbolism. One could almost perceive the missing elements, fire and earth, in the very texture and colour of the printing medium. And the menacing beauty of this rich impression well conveys the dangers of sensorial immersion in the physical world. The artist has successfully adapted his semantic intentions to productive constraints; but this compromise itself seems unsatisfactory, as the return of the full motif in later versions (copies A, B and G for example) suggests.

The unstable, tentative and open-ended nature of the Urizen colour printed versions presents in dramatic terms what was to become a central feature of Blake's later prophecies and the redemptive impetus of the state of Generation: the endless struggle of formal and artistic production. The self- 
reflexive designs in Urizen suggest that this emphasis on the very process of form-making was anchored in the reality of the artist's own struggle at the time. The intractability of colour printing appears to have undermined both his desire to achieve artistic immediacy through a renewal of graphic techniques, and his aspirations to "minute neatness of execution." His temporary disappointment is hinted at in the last lines of The Book of Los, produced in 1795, which thematically and stylistically completes the Urizen sequence:

\section{a Form}

Was completed, a Human Illusion

In darkness and deep clouds involvd

E94

At this conclusive moment, Mitchell points out, Blake appears "to step outside of his own work and find it less than good" (107). His achievement has little to do with what he elsewhere praises as the clear and definite forms of the imagination. It is an indefinite and unreal shape, still immersed within the world of sense and surrounded by Burkean darkness.

Nevertheless, as Mitchell adds, the word "illusion" "inevitably evokes its contrary, pointing to the possibility of creating a 'real' human form" (114). Blake would have conceived such a "real" form as existing in the imagination, rather than in the world perceived by the senses. When he described his painting of the Last Judgment, he asserted that the world of Imagination "is Infinite and Eternal whereas the world of Generation or Vegetation is Finite \& Temporal There Exist in that Eternal World the Permanent Realities of Every Thing which we see reflected in this Vegetable Glass of Nature" (E555).

In spite of its obvious Platonic inspiration, this conception goes against Plato's belief that artistic representation will always be a shadow of a superior intellectual reality. Instead, it highlights the challenging task of the artist whose duty it is to actualize the perfect forms of his imagination. Blake's choice as an artist to visualize what addressed the Eye of the Imagination plunged him into the materiality of formal production. It also made him crucially aware of the conflict between the aspiration to formal perfection and the resistance of the artist's materials and execution. In Urizen, the textual and visual representations of the process of form-making, however clumsy and incomplete its momentary productions may be, may be an expression of this awareness. It is better to present the imperfect and unfinished forms of the designs than no form at all, and to laboriously strive to convey the more real forms of the imagination than to renounce visual representation. Even Urizen's production of petrified and grotesque forms is not entirely sterile. He and Los, in their own way, initiate the struggle to retrieve form out of vacuity and formlessness. 


\section{Conclusion: Sublimity and Formal Inadequacy}

The Book of Urizen, then, could be said to dramatize an awe-inspiring quest, whose end is to match artistic representation with the forms of the imagination. It raises the essential question of whether the physical forms of artistic execution can ever match or give an adequate idea of the "infinite" forms of the imagination. Even though Blake believes that human perception should embrace the infinite, and therefore refutes the idea of sublimity as a transcendent experience, Urizen demonstrates his painful awareness of incommensurability between imaginative perception (which is infinite) and artistic representation (which is finite). It is in this discontinuity between imaginative form and visual form that one should look for a Blakean sublime, as an experience immanent to artistic activity, and to Blake's own production. Quite meaningfully, these are issues which are central to several theories of the sublime, where representational effort driven by the terror of inadequacy is a common pattern. Such a pattern was most clearly demonstrated in Immanuel Kant's Critique of the Power of Judgment, where the sublime arises from the powerlessness of the imagination (as the faculty of presentation) to give form to what "cannot be contained in any sensible form, but concerns only ideas of reason" (129). Although Kant's conception of the imagination as a "sensible faculty" (141) reverses the Blakean approach, Vincent De Luca is right to observe that "Blake's and Kant's defining conditions for the sublime have, mutatis mutandis, an identical structure. What is a barrier to the faculty allied with sense is an avenue to its more privileged counterpart" (25).

A similar pattern has also been given prominence by Kant's recent commentators. Among them, JeanFrançois Lyotard, Jacques Derrida, or Jean-Luc Nancy have emphasized that the sublime is primarily a process, driven by the desire to give form to what exceeds form or, as Lyotard puts it, "to present the fact that there is an unpresentable" (Lyotard 206). All insist that the sublime is immanent to the openended process of form-making, of filling the canvas (Lyotard) or of drawing the line that stands between the finite and the infinite (Derrida, Nancy). Nancy in particular shows that the emergence of the thought of the sublime was the recognition that there is no end to art, that it is pure presentation, "form forming itself, for itself, without object." The completion of form through contours, in this view, is superseded by the gesture, the act of delineation itself, "by which all (finite) form gets carried away into the absence of form" $(29,36)$.

Although Blake is not explicitly formulating a new theory of the sublime in such terms, his concern with form-making and his display of formal inadequacy, seen in the light of his later advocacy of linear accuracy and vigour, demonstrates similar dynamics. The Book of Urizen does present the fact that there is an unpresentable, that visual form tends towards ends that are beyond its grasp, and that what matters primarily is the creative act, the process of form-making, however tentative it may be. It is this occurrence, the event of artistic production, that dispels the "possibility of nothing happening," of vacuity and chaos taking over from the eternal forms of the imagination. The dismal Burkean void opened at the beginning of The Book of Urizen consequently becomes the scene of an intense effort to reclaim forms from nothingness, which is in itself sublime. Later, Blake was to show more confidence 
in this creative act, as his bold defense of his own linearism was to make clear. For the time being, The Book of Urizen brings together in a dramatic manner the terror of Burkean aesthetics and the dynamics of Kantian theory, in a most compelling illustration of the sublime anxiety of artistic creation.

\section{Note biographique}

Hélène Ibata is senior lecturer at the English Department of the University of Strasbourg (France). She is the author of a doctoral thesis on William Blake (William Blake: I'invention d'une esthétique), and has been publishing articles on British art of the $18^{\text {th }}$ and $19^{\text {th }}$ centuries, focusing on the art of J.M.W. Turner, William Blake, and the question of the sublime.

\section{Bibliography}

Barr, Mark L. "Prophecy, the Law of Insanity, and The [First] Book of Urizen." Studies in English Literature 46.4 (2006): 739-62. Print.

Google Scholar

Burke, Edmund. A Philosophical Enquiry into the Origin of our Ideas of the Sublime and the Beautiful. 1757. Oxford: Oxford University Press, 1990. Print.

Google Scholar

Burke, Edmund. Reflections on the Revolution in France. 1790. Harmondsworth: Penguin, 1986. Print. Google Scholar

Chernik, Aria. "The 'Peculiar Light' of Blakean Vision : Reorganizing Enlightenment Discourses and Opening the Exemptive Sublime. "Romanticism and Victorianism on the Net 50 (2008) : 23 paragraphs. Online.

Google Scholar

Coleridge, Samuel Taylor. Lectures 1808-1 : On Literature. Ed. R.A. Foakes. 2 vols. The Collected Works of Samuel Taylor Coleridge. London and Princeton: Routledge and Kegan Paul and Princeton U.P, 1987. Print.

Google Scholar

Cooper, Andrew. "Freedom from Blake's Book of Urizen." Studies in Romanticism 48.2 (2009): 187-218. Print.

Google Scholar

De Luca, Vincent A. Words of Eternity: Blake and the Poetics of the Sublime. Princeton: Princeton University Press, 1991. Print.

Google Scholar

Derrida, Jacques. La Vérité en Peinture. Paris: Flammarion, 1978. Print. Google Scholar

Easson, Kay Parkhurst, and Roger R. Easson, eds. The Book of Urizen. London: Thames and Hudson, 1979. Print. 
Erdman, David. Blake Prophet Against Empire. $3^{\text {rd }}$ edn. Princeton: Princeton University Press, 1977. Print.

Google Scholar

Erdman, David V. The Illuminated Blake: William Blake's Complete Illuminated Works with a Plate-byPlate Commentary. New York: Dover Publications, 1974. Print.

Google Scholar

Erdman, David V., ed. The Complete Poetry and Prose of William Blake. Newly rev. ed. New York: Anchor Books, 1988. Print.

Google Scholar

Essick, Robert N. and Viscomi, Joseph. "An Inquiry into William Blake's Method of Color Printing." Blake/ An Illustrated Quarterly 35 (2002): 74-103. Print.

Google Scholar

Esterhammer, Angela. "Calling into Existence: The Book of Urizen." Blake in the Nineties. Ed. Steve Clark and David Worrall. Basingstoke: Macmillan; New York: St Martin's Press, 1999.

Google Scholar

Fairbanks, A. Harris. "Blake, Burke, and the Clanrickard Monument." Blake/ An Illustrated Quarterly 31.3 (1997-1998): 76-81. Print.

Google Scholar

Kant, Immanuel. Critique of the Power of Judgment. Trans. P. Guyer and E. Matthews Cambridge: Cambridge University Press, 2000. Print.

Google Scholar DOI:10.1017/CB09780511804656

Lyotard, Jean-François. "The sublime and the avant-garde." 1988. Trans. in The Lyotard Reader. Ed. Andrew Benjamin. Oxford : Blackwell, 1991. Print.

Google Scholar

Mann, Paul. "The Book of Urizen and the Horizon of the Book." Unnam'd Forms: Blake and Textuality. Ed. Nelson Hilton and Thomas A. Volger. Berkeley: University of California Press, 1986. 49-68. Print. Google Scholar

McGann, Jerome. "The Idea of an Indeterminate Text: Blake's Bible of Hell and Dr. Alexander Geddes." Studies in Romanticism 25.3 (1986): 303-24. Print.

Google Scholar DOI:10.2307/25600606

Mitchell, W.J.T. Blake's Composite Art: A Study of the Illuminated Poetry. Princeton: Princeton University Press, 1978. Print.

Google Scholar

Nancy, Jean-Luc. "The Sublime Offering." Of the Sublime: Presence in Question. Ed. Jean-François Courtine. Trans. Jeffrey S. Librett. Albany: State University of New York Press, 1993. Print. Google Scholar

Paley, Morton D. The Apocalyptic Sublime. New Haven and London: Yale University Press, 1986. Print. Google Scholar

Tannenbaum, Leslie. Biblical Tradition in Blake's Early Prophecies: The Great Code of Art. Princeton: 


\section{Princeton University Press, 1982. Print.}

Google Scholar

Viscomi, Joseph. Blake and the Idea of the Book. Princeton: Princeton University Press, 1993. Print. Google Scholar

Worrall, David, ed. William Blake: The Urizen Books. Blake's Illuminated Books, vol. 6. London: Tate Gallery Publications, for the William Blake Trust, 1995. Print.

Google Scholar

The William Blake Archive. Ed. Morris Eaves, Robert N. Essick, and Joseph Viscomi. July 14, 2009. http://www.blakearchive.org/. Online.

Google Scholar

\section{Notes}

[1] Although only copy G (a much later version of the book) is actually entitled The Book of Urizen, and the initial title, The First Book of Urizen, may be read as a parodic allusion to "the first book of Moses", the traditional name of Genesis, I will use the later title, which is conventionally accepted by Blake scholars.

[2] All quotations of Blake's work come from David Erdman's The Complete Poetry and Prose of William Blake (London, 1988). Erdman's edition will hereafter be indicated as 'E'. For the text of Urizen, one has to bear in mind the inconsistency of the numbering, due to Blake's reordering of plates from copy to copy.

[3] Another noteworthy analysis is provided by Mark L. Barr, who argues that in a context of close government scrutiny of potential textual sedition, Urizen was written in such a way as to circumvent censorship and the court of law, using "the fires of prophecy" as a mechanism to deny authorial intent. Other recent readings have emphasized the agency of the reader in a book which not only is a reflection about the production of the book itself (Mann, Cooper), but also creates a space of freedom for critique and interpretation (Cooper, Chernick).

[4] For the plate numbering, the references will be G.E.Bentley Jr, Blake Books: Annotated Catalogues of William Blake's Writings (Oxford: Clarendon Press, 1977) and David Erdman, The Illuminated Blake (Garden City, New York: Anchor Books, 1974). The references to individual copies of Urizen will be made through The William Blake Archive, the very complete Internet resource on William Blake. The William Blake Archive. Ed. Morris Eaves, Robert N. Essick, and Joseph Viscomi.

<http://www.blakearchive.org/>.

[5] A facsimile version of copy G, which stylistically stands apart from the earlier copies, can be found in The Book of Urizen, ed. Kay Parkhurst Easson and Roger R. Easson (London, 1979).

\section{Liste des figures}


Patrick Colm Hogan, Understanding Nationalism: On Narrative, Cognitive Science, and Identity. Columbus: The Ohio State University Press, 2009. ISBN: 978-081421107-6. Price: US\$69.95

By Anne Stiles

Timothy Morton. The Ecological Thought. Cambridge MA: Harvard University Press, 2010. ISBN: 978-0-674-04920-8. Price: US\$39.95

By Tobias Menely

Katherine Byrne. Tuberculosis and the Victorian Literary Imagination. Cambridge: Cambridge University Press, 2011. ISBN: 978-0-521-76667-8. Price: US\$90.00/£55.00

By Pamela Gilbert

Cockney Cities

By Jeffrey Cox

Subscribe to our newsletter name@email.com Sign Up

\section{About}

Subscriptions

\section{English}

Journals

Theses 


\section{Books and Proceedings}

Research reports

Help

Site Map

Contact Us

Never know too much

\section{érudit}

Cultivate your knowledge.

() 2017 Érudit Consortium

Terms and Conditions

Follow Us

$f y$ in 